Neville, F.G. (2015). Preventing violence through changing social norms. In P. Donnelly \& C. Ward (Eds.) Oxford Textbook of Violence Prevention (p239-244). Oxford: Oxford University Press.

\title{
Preventing Violence Through Changing Social Norms
}

\author{
Oxford Textbook of Violence Prevention: Epidemiology, Evidence, and Policy
}

\section{Fergus G. Neville}

\section{Theoretical overview}

Whilst some attempts to tackle violence at an individual level have been effective (e.g. anger management, partner communication, and parenting skills), they do not address the broader social context in which violence is rooted and perpetuated (Berkowitz 2004). Social norms interventions represent a strategy for violence prevention at a social level. Interventions at the psychological level of groups are appropriate in several ways. For instance, interpersonal' violence perpetration and victimisation are often framed by collective identities, even if an altercation only physically involves two people. Social norms are central to the way in which these collective memberships shape behaviour, and thus represent a potential opportunity for violence prevention. This chapter will not attempt to catalogue all violence prevention programmes which make use of social norms. Rather, the purpose will be to discuss initiatives which draw out key themes from which we can infer best practice. Before coming to these examples, it is necessary to first outline what social norms actually are, and why they are relevant to behaviour change, particularly with regards to violence prevention.

What are Social Norms?

Social influence research shows that people's behaviour is not determined simply by what they think, but by what they think other people like them think. In more technical terms, behaviour can be driven by the perceived social norms of fellow group members (Elcheroth et al. 2011; 
Smith and Louis 2009; Turner 1991). Although various definitions of social norms exist within the academic literature, there is general agreement that they refer to shared beliefs within a social unit about the appropriate ways to think, feel, and behave in a given context (Chekroun 2008; Turner 1991).

\section{Injunctive and Descriptive Norms}

Cialdini and colleagues (1990) further argue that there are two types of norms: injunctive norms refer to what members of a social unit ought (and ought not) to do, whilst descriptive norms refer to how most of them actually behave. Injunctive and descriptive norms can differ from one another. For example, whilst donating blood is generally seen as something one ought to do (an injunctive norm), regrettably few people actually do it (a descriptive norm). The distinction between these is of relevance to the design of social norm interventions. If a violence intervention only presents a group's descriptive norms (e.g. sexual assault statistics) then this may unintentionally increase the prevalence of the negative behaviour. This is because group members who did not originally act this way may begin to do so in an attempt to bring their own behaviour into line with the descriptive norm (Paul and Gray 2011). Misalignment of descriptive and injunctive norms may therefore explain the mixed efficacy of social norm campaigns.

Interventions that neglect social norms are also problematic. For example, Australian researchers demonstrated that a university 'sun-smart' drive could actually decrease sunscreen use if it failed to provide information regarding normative student behaviour (Smith and Louis 2009). This was because without normative information, students inferred from the need for a campaign that other students did not engage in, or approve of, sun protection - and they therefore used sun screen less, in order to fit in with their perceptions of the social norm. When participants were instead informed that the majority of students approved of sun protection behaviour, there was an increase in intended sunscreen use. The fact that the identity of the referent group in the second experimental condition was 'ingroup' - fellow students - is critical. 


\section{Social Norms and Social Identities}

Social norms are important, because they are the means by which social categories can influence their members' behaviour (Cialdini et al. 1990). Social identity research has shown that people are in possession of multiple identities - at both personal and group levels of self - which become salient in different social contexts (Reicher et al. 2010). People inside one's social group become ingroup members, and those outside become outgroup. As one defines or 'self-categorises' oneself in terms of different identities, one self-stereotypes and adopts the norms and behaviours associated with that relevant identity. For instance, in different situations I might think of myself as an academic, a father, or a football supporter. As each identity becomes more salient to me in different social contexts, my behaviour will be shaped by the social norms congruent with the relevant identity.

This body of work has contributed to social norm research by signifying that what is influential is not what just anybody thinks, but what others within one's salient social category thinks. This is because the normative position of fellow group members is recognised as subjectively valid (Duck et al. 1999; Turner 1991). This has particular practical relevance, because normative messages in public health interventions are typically from the perspective of outgroups (e.g. adults or health professionals), and not from salient and meaningful referent ingroups (Smith and Louis 2009; World Health Organisation 2009).

The recognition that groups have the ability to positively influence their members is a significant departure from classic group psychology, which viewed groups as inherently deleterious (e.g. Zimbardo 1969). Instead of being regarded as a threat, social group membership should instead be seen as an opportunity for positive social influence through social norms. This works both ways of course: social norms can drive negative behaviours as well as positive ones. Social groups should therefore be seen as neither intrinsically positive nor negative. The point is 
to be aware of the powerful role that social norms play in shaping behaviour, and to design violence prevention initiatives that can harness this power.

\section{Norm enforcement}

Social groups are able to influence behaviour because there is pressure to conform to a social norm which is a criterion of group membership. Individuals can be included or excluded from a social category based upon the fit of their behaviour relative to the norms of the group (Turner et al., 1987). Social pressure to conform may also be exerted through ingroup members communicating their disapproval of counter-normative actions, and via a fear of disapproval (and desire for approval) by ingroup members (Chekroun 2008). Moreover, because social norms operate as a function of internalised social identities, group members' behaviour can continue to be shaped by group norms when they are alone and not under observation (Hogg and Vaughan 2008).

In practical terms, this suggests a key and efficacious role for ingroup members in 'selfpolicing' the behaviour of fellow category members. This prospect is exemplified by an anecdote from an ethnographic study of football supporters (Stott et al. 2001). When Scotland fans - who pride themselves upon being non-violent and convivial - witnessed one of their own assault a Tunisian supporter during the 1998 World Cup in France, they violently attacked the Scottish perpetrator and shunned him for the remainder of the tournament. Not only did this action prevent an escalation of intergroup violence, it reinforced the norm amongst Scottish fans that violence against supporters of other teams was socially unacceptable. Whilst violent intervention is hardly an ideal model of violence prevention, the example does illustrate the significant role that ingroup members play in regulating one another's behaviour.

\section{The Status of the Evidence}


There is a growing body of evidence which demonstrates that carefully designed social norm interventions can successfully reduce problematic social behaviours, and encourage desirable ones. However, at present social norm interventions with a view to violence prevention remain relatively under-evaluated. What little work has been done has generally focussed upon gender violence interventions in universities. This is in large part due to ease of access to participants, particularly when the interventions have been designed by academics. These interventions can function as a useful starting point in the development of a roadmap for constructing thoroughlyevaluated social norms interventions into a variety of forms of violence.

\section{Brief Description of Intervention Procedures}

\section{Gender and Sexual Violence}

Gender and sexual violence social norm interventions are typically premised upon the influence of (mis)perception of peer attitudes and behaviours. Although the majority of men may disapprove of violence against women, this view is often not expressed if men do not gauge their peers as sharing this view (Fabiano et al. 2003). This can create a cognitive error such that lack of expressed peer disapproval is taken by perpetrators as tacit approval of their behaviour - by fellow ingroup members no less - thereby perpetuating future abuse (Baer et al. 1991). Indeed, in community samples of American men, perpetrators of gender violence typically overestimate both peers' support for forced sex (Abbey et al. 2007) and the prevalence of gender violence amongst other males (Neighbours et al. 2010), and individuals who perceive their peers to find sexual aggression acceptable also score highly on measures of sexual aggression (Loh et al. 2005). As Tharp and colleagues note, peer groups which contain at least one member who engages in sexual violence but is not challenged can lead to a group norm which supports and normalises violent sexual behaviour (Tharp et al. 2013). 
Bohner and colleagues (2006) used an experimental paradigm to provide further evidence of the importance of perceived social norms in this context. Male university students were presented with false feedback indicating that their male peers had either very high or low rape myth acceptance. Participants in the first condition subsequently reported a significantly greater willingness to rape than participants in the second. This simple study illustrates the critical role that men who object to gender violence have to play in its prevention, through expression of their collective opposition and assertion that the behaviour is counter-normative.

This is because, whilst a perceived group norm supportive of gender violence can inhibit intervention, a belief that fellow group members share one's willingness to intervene can facilitate perpetrator confrontation (Brown and Messman-Moore 2009). For example, male undergraduates' self-reported willingness to intervene in sexual violence is significantly predicted by their perception of how likely other males (but not females, i.e., only a meaningful referent ingroup) are to intervene (Fabiano et al. 2003). The correction of misperceived ingroup norms concerning gender violence therefore presents an opportunity to design social norm violence prevention interventions. Moreover, this work points to the importance of designing interventions aimed at entire cohesive social groups, and not just known perpetrators (Gidycz et al. 2001).

An example of a successful social norms programme based upon this approach is described by Gidycz et al. (2011), who worked with male undergraduate students. In addition to strategies designed to increase empathy with females and promote understanding of consent, the programme presented normative feedback on campus-wide male discomfort with sexual assault and aggression, and encouraged male participants to express their own opposition to gender violence. This functioned to undermine mistaken perceptions of comfort with sexual assault, and validate a positive majority norm of intervention into the behaviour of a minority. Evaluation of the initiative concluded that relative to a control group, programme participants self-reported 
less sexual aggression at a 4-month follow-up, and a greater expectation that peers would intervene in incidents of gender violence.

Another illustrative example of a promising social norms programme is the Mentors in Violence Prevention initiative (MVP; Katz 1995). This was designed specifically to provide bystanders - who are often seen as peripheral to interpersonal violence - with the tools to intervene through discouragement, prevention, and interruption. To date MVP has been widely implemented in the United States with professional sports teams, the military, and high schools students, and is currently being piloted with young people in Scotland and Sweden. MVP is a form of peer-led learning such that ingroup members (e.g. players in one's sports team or students in one's class) are trained to deliver sessions to their peers. The sessions involve discussion of a variety of gender violence scenarios, and of options in how best to respond to them. Doing nothing is never seen as an acceptable strategy. Peer-group audiences are singlegender in order to facilitate an honest discussion of experiences and views without embarrassment.

The role of social norms is critical to MVP in at least three ways. First, participants are encouraged to discuss issues of gender violence with other ingroup members, and to reach a consensus position in opposition to it. Second, the programme aims to shift social norms to facilitate empowerment and intervention. Third, interventions should then reinforce and validate the social norm that gender violence is unacceptable, and that intervention is normative. MVP is also designed to deliver practical intervention strategies, and is thus congruent with Berkowitz's (2004) assertion that men are more receptive to positive practical messages rather than negative approaches which focus on blame. Evaluations to date suggest that MVP participants are more likely to intervene in situations of gender violence than non-participants (e.g. Katz et al. 2011).

One of the reasons why MVP appears to be successful is because the normative influence comes from ingroup peers and not outsiders. This notion is also central to the 
CeaseFire programme (alternatively named Cure Violence), a U.S.-based initiative designed to mediate street conflicts before they lead to serious violence (Whitehill et al. 2013). Outreach workers ('violence interrupters') are employed from the communities in which they work, and often have a personal history of gang involvement and incarceration. These individuals are seen as 'credible messengers', and have the contacts and skills to encourage protagonists' peers to assert influence to avoid violent outcomes. The prevention of one violent incident may then avert future retaliatory attacks, and also demonstrate that conflicts may be resolved without the use of force. Furthermore, CeaseFire encourages community events (marches, vigils, etc.) against violence, thereby explicitly communicating a collective desire for peace, and not tacit approval for street violence which may result from community silence. Initial evaluations of the approach indicate a promising decrease in gun crime and homicides (e.g. Webster et al. 2012), although it is difficult to isolate the specific role of social norms from the programme's various conflict mediation strategies.

\section{Edutainment}

Educational entertainment ('edutainment') campaigns have attempted to shift social norms and attitudes to violence through the media. For example, a radio soap-opera in post-war Rwanda explored issues of tribalism, retaliation, and cooperation. Paluck (2009) demonstrated that over the course of a year listeners' personal attitudes towards these issues remained stable, but that they experienced positive change in their perceptions of ingroup norms. Participants listened to and discussed the shows in groups of peers, and it was this communication of other's normative positions which Paluck argued was crucial to the normative change.

\section{Alcohol and Violence}

Whilst excessive alcohol intoxication (and other forms of substance misuse) does not inevitably lead to violent behaviour, it is a risk factor for violence. Given this relationship, social norm 
interventions designed to attenuate alcohol intake may act as indirect violence interventions (WHO 2009). There are several ways in which social norms are relevant to alcohol and violence. For example, cultures which tolerate greater levels of alcohol abuse display a stronger link between violent behaviour and alcohol consumption, and a social belief that alcohol provides courage may lead to alcohol consumption before the perpetration of violence (WHO 2009). Interventions which correct mistaken perceptions of peer norms regarding excessive alcohol consumption (so called 'pluralistic ignorance'; Perkins and Berkowitz 1986; Prentice and Miller 1993) have successfully reduced alcohol consumption, and therefore address a key risk factor in violence perpetration and victimhood.

\section{Community Social Norm Change: A Case Study}

Deep-rooted cultural practices and beliefs can provide a potential challenge to a social norms approach to violence prevention. Interventions implemented by outsiders are often ineffective at changing behaviours which are seen as integral to a group's social identity. Female genital mutilation (FGM) - described as 'de facto violent' by UNICEF (2013) - in rural Senegal was regarded as one of these issues. Attempts to stop FGM as a cultural practice by non-community members failed, and an official law passed against the practice had little impact. Nonconformation with the circumcision norm could lead to exile from the social group, in part due to a cultural belief that not undergoing the operation could spiritually endanger both the individual and the community. Norm enforcement was therefore viewed as a form of individual and collective protection.

However, since 1998 a collective movement led by villagers at a community level has substantially reduced the practice using a social norms approach (Melching 2012). First, villagers came to a consensus around their community goals which included well-being and health. A sustained period of community discussion and reflection then concluded that FGM was incongruent with these goals. Crucially, a new norm of not circumcising was framed not as an 
attack upon tradition, but rather as a means of enacting long-standing community norms of health. Next, community members publically denounced FGM, and expressed commitment to the sanctioning of individuals who violated the new norm. It was this shift in social norms with community-led sanctions that led to behaviour change. Despite FGM being outlawed in Senegal, it was only the change in 'community law' which allowed families to disregard the traditional practice without fear of community repercussion (Melching 2012).

This case study is a useful way of summarising many of the key points outlined in this chapter. The first is that the social identity of the target population is crucial in a number of ways. A cohesive social group is necessary for intragroup social influence through public support for social norms of non-violence, and community-led 'self-policing' or sanctions for group members who act in defiance of collective norms. Second, the adoption of non-violent social norms must be congruent with a group's self-identity. Finally, the intervention only worked when it was owned by ingroup members and not outsiders. Whilst there can be a role for external organisations in implementing non-violence interventions, the very nature of social influence determines that social norm change must be driven by prototypical ingroup members.

\section{Transportability of Programmes Nationally and Internationally}

\section{Common Process, Bespoke Content}

In order for a social norms approach to be effective, it must articulate with the target group's social identity. Since a group's norms are embedded in social context, any initiative will need to account for this context. This means that although the processes of norm and behaviour change will remain constant between programmes, the content of the details will necessarily vary in order to be culturally relevant. Social norm interventions are therefore transportable nationally and internationally, so long as they are contextually sensitive. For instance, group-specific 
statistics are more powerful than general figures, and interventions must consider the culture and goals of the group.

The importance of designing bespoke norm interventions for different social groups was demonstrated in the evaluation of a social norms campaign regarding sexual consent for deaf and hard-of-hearing students (White et al. 2003). The implementation of a campus-wide initiative was initially unsuccessful for this sub-group. The programme was then re-designed to be specifically relevant for this population, including a consideration of their communication style and culture. There was a subsequent decrease in sexual assaults in this group only after the bespoke intervention was implemented.

\section{Gaps in the Evidence}

Whilst existing research offers preliminary hope for the utility of social norms interventions in violence prevention, there remains a need for high-quality evaluations of theoretically-based programmes. At present many interventions are not underpinned by theory (Paul and Gray 2011), and do not undergo rigorous evaluation. The evaluations that are conducted generally only employ self-report attitudinal measures which may not correspond to behaviour change outcomes around violence perpetration or bystander intervention (ibid). This is partly because of demand characteristics around topics such as sexual assault (i.e., participants are unlikely to reveal support for sexual assault if they expect this response to be negatively evaluated by the researcher; Breitenbecher 2000), and also due to the relatively low perpetration rates in researchers' favourite population of choice - university undergraduates. Although this is a useful group with which to pilot interventions (particularly around sexual assault and alcohol), the field should progress to populations at greater risk of violence perpetration, and also consider the addition of behavioural measures and routinely collected criminal justice data. 
An improvement in evaluation design would also allow conclusions to be drawn with greater certainty about the efficacy of interventions. For example, at present many evaluations do not include suitable comparison groups. Evaluating attitude or behaviour change at a one-year follow-up requires a non-intervention comparison group to determine whether any postintervention differences are due to the programme, or other factors such as maturation effects (particularly likely with student populations) (Paul and Gray 2011). It is particularly important for future evaluations to measure what participants think their peers believe, in addition to their personal opinions. As this chapter has argued, change in the epistemic relationships between group members at a meta-representational level is central to normative and behavioural change, but is seldom measured.

Random assignment into research conditions would also improve the quality of evaluation. This is often practically challenging because violence prevention strategies are typically designed to target specific problematic groups. Although randomisation at an individual level may be unrealistic, random allocation at the level of the group (e.g. school, neighbourhood etc.) might be achievable (Paul and Gray 2011). Furthermore, a movement toward mixedmethods evaluations would also allow researchers to capture the qualitative richness that is inherent in social norms interventions, in addition to survey and routinely collected quantitative data.

A more thorough description of research methods and intervention implementation would also improve the evidence base. At present these sections of evaluations are often sparse, creating ambiguity about which elements of an intervention worked and why (Paul and Gray 2011). More precise description of intervention implementation and an effort to specifically evaluate all elements of this in a macro fashion will result in a clearer picture of the effectiveness of the social norms component (see chapter 18 of this volume). Finally, many evaluations fail to include a long-term follow-up of intervention. This is in part a consequence of the ephemeral 
nature of research funding. Nonetheless, an effort to explore how social norms violence interventions affect attitudes, norms, and behaviours in the long-term is essential for the design of future programmes including their projected cost-effectiveness.

\section{Conclusions}

A social norms approach to violence prevention has gained traction is recent years, and incipient evaluations have yielded promising results. This chapter has reviewed the theory underpinning a social norms approach to violence prevention, and has discussed a variety of interventions in order to draw out key themes. The first point to note is that norms are the mechanism by which social categories influence their members. Psychological groups should therefore be reconceptualised as a resource - and not a threat - in violence prevention. Behaviour is also commonly driven at a meta-representational level by the perceived norms of ingroup members, and thus ingroup peers have a key role to play in preventing violence. The perceptive element of this is a fertile area for social norms interventions, through correction of misperceptions about others' attitudes and behaviours. This is good news for practitioners, because altering the epistemic relationships between group members is a substantially easier task than trying to simultaneously change everyone's personal attitudes. In practical terms, social norms violence interventions will work best when designed to target cohesive groups in order to encourage peer influence and 'self-policing'. Bespoke programmes should be designed for specific social units in order to be culturally relevant and efficacious, and both descriptive and injunctive norms should be utilised to prevent counterproductive effects. Interventions should also be delivered from the perspective of ingroup members, and behaviour change should be consonant with defining tenets of the target group's identity.

\section{Acknowledgements}


Page 14 of 18

The author wishes to thank the editors and multiple colleagues for constructive comments on earlier drafts of this manuscript. 


\section{References}

1. Abbey, A., Parkhill, M., Clinton-Sherrod, A., and Zawacki, T. (2007). A comparison of men who committed different types of sexual assault in a community sample. Journal of Interpersonal Violence, 22, 1567-80

2. Asch, S. E. (1951). Effects of group pressure upon the modification and distortion of judgment. In: H. Guetzkow (ed.). Groups, leadership and men. Oxford: Carnegie Press, pp. 177190

3. Baer, J. S., Stacy, A., and Larimer, M. (1991). Biases in the perception of drinking norms among college students. Journal of Studies on Alcohol, 52, 580-6

4. Berkowitz, A. D. (2004). Working with men to prevent violence against women: program modalities and formats (part two). Violence Against Women Resource Network. Available at www.vawnet.org. [Accessed 2 February 2013].

5. Bohner, G., Siebler, F., and Schmelcher, J. (2006). Social norms and the likelihood of raping: perceived rape myth acceptance of others affects men's rape proclivity. Personality and Social Psychology Bulletin, 32, 286-97

6. Breitenbecher, K. H. (2000). Sexual assault on college campuses: is an ounce of prevention enough? Applied and Preventive Psychology: Current Scientific Perspectives, 9, 23-52

7. Brown, A. L. and Messman-Moore, T. L. (2009). Personal and perceived peer attitudes supporting sexual aggression as predictors of male college students' willingness to intervene against sexual aggression. Journal of Interpersonal Violence, 25, 503-17

8. Chekroun, P. (2008). Social control behavior: the effects of social situations and personal implication on informal social sanctions. Social and Personality Psychology Compass, 2, 2141-58

9. Cialdini, R. B., Reno, R. R., and Kallgren, C. A. (1990). A focus theory of normative conduct: recycling the concept of norms to reduce littering in public places. Journal of Personality and Social Psychology, 6, 1015-26 
10. Duck, J. M., Hogg, M. A., and Terry, D. J. (1999). Social identity and perceptions of media persuasion: are we always less influenced than others? Journal of Applied Social Psychology, 29, 1879-99

11. Elcheroth, G., Doise, W., and Reicher, S. D. (2011). On the knowledge of politics and the politics of knowledge: how a social representations approach helps us rethink the subject of political psychology. Political Psychology, 32, 729-58

12. Fabiano, P. M., Perkins, H. W., Berkowitz, A., Linkenbach, J., and Stark, C. (2003). Engaging men as social justice allies in ending violence against women: evidence for a social norms approach. Journal of American College Health, 52, 105-12

13. Gidycz, C. A., Orchowski, L. M., and Berkowitz, A. D. (2011). Preventing sexual aggression among college men: an evaluation of a social norms and bystander intervention program. Violence against women, $17,720-42$

14. Goldstein, N. J., Cialdini, R. B., and Griskevicius, V. (2008). A room with a viewpoint: using social norms to motivate environmental conservation in hotels. Journal of Consumer Research, 35, $472-82$

15. Hogg, M. A and Vaughan, G. M. (2008). Social Psychology (Fifth Edition). Harlow: Pearson. 16. Katz, J. (1995). Reconstructing masculinity in the locker room: the Mentors in Violence Prevention Project. Harvard Educational Review, 65, 163-75

17. Katz, J., Heisterkamp, H. A., and Fleming, W. M. (2011). The social justice roots of the mentors in violence prevention model and its application in a high school setting. Violence Against Women, 17, 684-702

18. Loh, C., Gidycz, C. A., Lobo, T. R., and Luthra, R. (2005). A prospective analysis of sexual assault perpetration: Risk factors related to perpetrator characteristics. Journal of Interpersonal Violence, 20, 1325-48

19. Melching, M. (2012). Creating social norms to prevent violence against girls and women. UN Women Expert Group Meeting, Bangkok. 
20. Neighbors, C., Walker, D. D., and Mbilinyi, L. F. et al. (2010). Normative misperceptions of abuse among perpetrators of intimate partner violence. Violence Against Women, 16, 370-86

21. Paluck, E. L. (2009). Reducing intergroup prejudice and conflict using the media: a field experiment in Rwanda. Journal of Personality and Social Psychology, 96, 574-87.

22. Paul, L. A., and Gray, M. J. (2011). Sexual assault programming on college campuses: using social psychological belief and behavior change principles to improve outcomes. Trauma, Violence, \& Abuse, 12, 99-109

23. Prentice, D. A., and Miller, D. T. (1993). Pluralistic ignorance and alcohol use on campus: some consequences of misperceiving the social norm. Journal of Personality and Social Psychology, 64, 243-256.

24. Reicher, S. D., Spears, R., and Haslam, S. A. (2010). The social identity approach in social psychology. In: M. S. Wetherell and C. T. Mohanty (eds.). Sage Handbook of Identities London: Sage, pp. 45-62.

25. Smith, J. R., and Louis, W. R. (2009). Group norms and the attitude-behaviour relationship. Social and Personality Psychology Compass, 3, 19-35

26. Stott, C., Hutchison, P., and Drury, J. (2001). Hooligans' abroad? Inter-group dynamics, social identity and participation in collective 'disorder' at the 1998 World Cup Finals. British Journal of Social Psychology, 40, 359-84

27. Tharp, A. T., DeGue, S., Valle, L. A., Brookmeyer, K. A., Massetti, G. M., and Matjasko, J. L. (2013). A systematic qualitative review of risk and protective factors for sexual violence perpetration. Trauma, Violence, \& Abuse, 14, 133-67.

28. Turner, J. C. (1991). Social Influence. Milton Keynes: Open University Press.

29. Turner, J. C., Hogg, M. A., Oakes, P. J. Reicher, S. D., and Wetherell, M. S. (1987). Rediscovering the Social Group: A Self-Categorization Theory. Oxford: Blackwell.

30. UNICEF (2013) Child Protection from Violence, Exploitation and Abuse. Available at: http://www.unicef.org/protection/57929 58002.html [Accessed 17 January 2013]. 
31. Webster, D. W., Whitehill, J. M., Vernick, J. S., and Curriero, F. C. (2013). Effects of Baltimore's Safe Streets program on gun Violence: a replication of Chicago's CeaseFire program. Journal of Urban Health, 90, 1-14.

32. White, J. A., Williams, L. M., and Cho, D. (2003). A social norms intervention to reduce coercive sexual behaviors among deaf and hard-of-hearing college students. The Report on Social Norms, 2, 1-8.

33. Whitehill, J. M., Webster, D. W., Frattaroli, S., and Parker, E. M. (2013). Interrupting violence: how the CeaseFire program prevents imminent gun violence through conflict mediation. Journal of Urban Health.

34. World Health Organization. (2009). Violence Prevention: The Evidence. Changing Cultural and Social Norms that Support Violence. Available at: http://www.who.int/violence injury prevention/violence/4th milestones meeting/publicat ions/en/ [Accessed 17 January 2013].

35. Zimbardo, P. G. (1969). The human choice: individuation, reason, and order versus deindividuation, impulse and chaos. Nebraska Symposium on Motivation, 17, 237-307. 